\title{
Theories of Pedagogic Codes and Knowledge Structures and Their Development
}

\author{
Jiangping Zhou ${ }^{1,2}$ \\ ${ }^{1}$ China West Normal University, Nanchong, China \\ ${ }^{2}$ Peking University, Beijing, China \\ Email: zhoujp@pku.edu.cn
}

How to cite this paper: Zhou, J. P. (2020) Theories of Pedagogic Codes and Knowledge Structures and Their Development. Open Journal of Social Sciences, 8, 105-110. https://doi.org/10.4236/jss.2020.88008

Received: July 17, 2020

Accepted: August 14, 2020

Published: August 17, 2020

Copyright (c) 2020 by author(s) and Scientific Research Publishing Inc. This work is licensed under the Creative Commons Attribution International License (CC BY 4.0).

http://creativecommons.org/licenses/by/4.0/

\begin{abstract}
This paper profiles the pathway from Bernstein's code theory and knowledge structure to Halliday's grammatical metaphor. It firstly delineates the theorizing of code theory and knowledge structure, and subsequently describes the process of associating itself with Karl Maton's legitimate code theory. Finally, drawing upon the semantic dimension of legitimate code theory, that is, semantic density and semantic gravity, Halliday's grammatical metaphor is expounded sociologically.
\end{abstract}

\section{Keywords}

Code Theory, Legitimate Code Theory, Semantic Density, Semantic Gravity, Grammatical Metaphor

\section{Introduction}

The theory of pedagogic sociology, proposed by the British eminent pedagogic sociologist Basil Bernstein, is one of the most significant theories in the field of sociology, which influences later researches not only in sociology (e.g. Maton, 2013, 2014; Wignell, 2007) but also in linguistics (e.g. Halliday \& Matthiessen, 2004; Martin, 2013). What is worth of mentioning is his code theory, which was put forward in the 1960s, and the theory of knowledge structures proposed in 1990s. Both of the two theories are incorporated and further delineated in his later monograph, entitled Pedagogy, Symbolic Control and Identity in 2000. One of the theories directly influenced by and associated with Bernstein's code theory and knowledge structure is Karl Maton's (2014) Legitimate Code theory (hereafter LCT), which by and large incorporates five different dimensions. The semantic dimension is to be elucidated while the others will be precluded in the following discussions. Functioning as an intermediate theory, the LCT bridges the 
association of Bernstein's theories with those in Systemic Functional Linguistics or SFL, prominently, the grammatical metaphor. In the following, therefore, the ideas about code theory and knowledge structure are explained first, and then their influences on the formation of LCT are expounded; specifically, the semantic dimension of the LCT is paid solely attention to, and the final section is devoted to the exemplification and association of semantic dimension with grammatical metaphors.

\section{Bernstein's Code Theory and Knowledge Structure}

According to Bernstein (2000), there was a lack of language that was employed to clearly articulate the distinction between modes of elaborated codes, nor did the discourse separate itself from the form of its transmission and evaluation. After delving into the inequality in pedagogy by briefly investigating the learners from working and middle classes, he found that these learners were fundamentally different in employing their languages while communicating with the outside world, that is, different codes would be adopted: Restricted Codes and Elaborated Codes (Bernstein, 1970, 1986, from Zhu, 2011). He hence, in examining the underlying reasons, formulated the code theory, which partly originated from Durkheim classification and was also influenced by the concept of framing from the early symbolic interactions, albeit they were defined with a different vantage point (Bernstein, 2000).

In Bernstein's sense, the concept of classification was employed to denote "the relations between categories, these relations being given by their degree of insulation from each other" (Bernstein, 2000: p. 99). It was power relations that maintained the degree of insulation and classifying regulations. Hence, categories were created and clearly bounded by strong insulation while the weak insulation would lead to blurred categories. The classification could be strong $(+C)$ or weak $(-C)$ relying on the degree of insulation, and it could also be internal $( \pm C)$ such as the relation between objects or persons within a classroom, or external $\left( \pm C^{c}\right)$ as the relation between school subjects. With respect to framing, it could be defined as "the locus of control over the selection, sequencing, pacing and criteria of the knowledge to be acquired" (ibid.). As with classification, framing was demarcated between strong $(+F)$ and weak $(-F)$, and internal $( \pm F)$ and external $\left( \pm F^{k}\right)$. The degree of classification and framing as a whole projects that of the social control, in other words, strong classification and framing construct an independent and clear boundary between subjects, and vice versa. Thus, codes can be generally understood as a tension between classification and framing $(\mathrm{Hu}, 2018)$. The features of classification and those of framing in the theory of pedagogic codes were written by Bernstein (1996: p. 29; 2000: p. 100) as:

$$
\frac{E}{ \pm C^{i e} / \pm F^{i e}}
$$

While outlining a model of knowledge practices, Bernstein firstly distinguished 
between vertical and horizontal discourses and then between knowledge structures within vertical discourse (Bernstein, 2000: p. 156). Horizontal discourse refers to daily or "commonsense knowledge and entails a set of strategies which are local, segmentally organized, context specific and dependent" (ibid.: 157). In contrast, vertical discourse refers to "specialized symbolic structures of explicit knowledge and takes the form of a coherent, explicit, and systematically principled structure" (ibid.: 157). Within vertical discourse, there are hierarchical knowledge structure and horizontal knowledge structure. The former refers to the integration of new knowledge through extending previous one, while the latter is the accumulation of knowledge in a linear order, which could be identified within the Humanities and Social Sciences (ibid.). The major difference is that the one is integration of knowledges while the other is accumulation of knowledges.

With respect to either the theory of pedagogic codes or that of knowledge structures, the idea of dichotomy threads through the whole process of Bernstein's architecture in terms of the two theories. However, this partially seems to be right on target. In addition, the dichotomous feature of pedagogic codes clarifies the boundaries among different categories at the expense of the inherent nature of categories being blurring. To be more precise, the boundaries of categories are not clear cut, but a line of continuum. The dichotomy of discourse and knowledge structures misleads us that they are either vertical/hierarchical or horizontal, and precludes the grey area that lies somewhere in between. Besides, it does not expound what underlies the vertical or horizontal discourse, or hierarchical or horizontal knowledge structures. Underlying these unspecified properties, Karl Maton's LCT, precisely, its dimension of semantics, is gradually filling the gap.

\section{The Semantic Dimension of LCT}

Semantic dimension is one of the five dimensions of LCT, which further develops rather than simply displaces the frameworks of Pierre Bourdieu's "field theory" and Basil Bernstein's "code theory" (Maton, 2014). Semantics incorporates semantic gravity and semantic density. The former refers to the degrees of context-dependence of meaning, and the latter is defined as the degree of condensation of meaning within socio-cultural practices (Maton, 2013, 2014). Both concepts can be relatively stronger $(+)$ or weaker $(-)$ within the intermediate degrees of the continuum. What they differ is that the stronger the semantic gravity (SG+), the more dependent the meaning is on its context, thus, experiencing a process of strengthening the semantic gravity ( $S G \uparrow$ ), and the weaker the semantic gravity (SG-), the less context-dependent the meaning is, hence weakening the semantic gravity ( $S G \downarrow$ ). On the contrary, the stronger the semantic density $(\mathrm{SD}+)$, the more meanings are condensed within practices; the weaker the semantic density (SD-), the less meanings are condensed. In this sense, the semantic density is either being strengthened ( $\mathrm{SD} \uparrow$ ) or being weakened (SD $\downarrow$ ). Subsequently, various semantic codes (SG+/-, SD+/-) are gener- 
ated pertaining to the relative strength of semantic gravity and semantic density, which is visualized by the following Figure 1 (Maton, 2014: p. 196).

The topological figure combines the concepts and boundaries with continua, and creates four code quadrants with dynamic processes of strengthening and weakening (SG $\uparrow \downarrow, \mathrm{SD} \uparrow \downarrow$ ).

\section{Association of Semantics with Grammatical Metaphor}

Grammatical metaphor is an important concept proposed by Halliday in SFL. Its first appearance was in Halliday (1984) and a year later theorized in his monograph An Introduction to Functional Grammar (Halliday, 1985). Halliday (1985, 1994) argued that there was at least one kind of congruent realization in the lexico-grammatical level for the semantic configuration, and there were then some other transferred or metaphorical realizations in some respects. Two main types of GM were described: ideational metaphor and interpersonal metaphor. During the early stages of exploration of GM, it was generally dichotomously oriented. That is to say, an expression is either congruent or metaphorical. However, this dichotomous feature, as that in Bernstein's theory of pedagogic code and knowledge structures, does not always hold water, specifically, an expression can be congruent in one context while metaphorical in another. Recently, systemists (Halliday \& Matthiessen, 2004; Yang, 2019) have reached an agreement that a congruent expression may move towards the metaphorical, and the various realizations in the intermediate level are more or less metaphorical or metaphorical syndromes. In other words, the most congruent and the most metaphorical set up a continuum, which is in accordance with the semantic dimension of LCT. In this respect, the dynamic changes of GM are associated with the semantic gravity and semantic density within the semantics of LCT. For example, the following clauses are quoted from Halliday \& Matthiessen (2004: p. 35).

1) Because osmolarity increases, putrescine is rapidly excreted.

2) Increases of osmolarity cause rapid excretions of putrescine.

3) Rapid excretions of putrescine through increases of osmolarity.

In a context of examples 1) and 2), 1) is congruent and 2) is metaphorical, because the two clauses in clause complex 1) are realized by a simple clause in 2), and the predicate verb cause in 2) is the verbalization of the conjunction because in 1). Nevertheless, in a context of examples 2) and 3), 2) becomes congruent and 3) becomes metaphorical because of the realization of a clause in 2) by a nominal group in 3). with respect to the metaphority, the three examples constitute a continuum from the least metaphorical 1) to the most metaphorical 3). Considering semantics in LCT, the semantic gravity through 1) to 3) is weakening (SG $\downarrow$ ) step by step along the line, because they are becoming less and less context-dependent; whereas the semantic density in the same sequence is strengthening ( $\mathrm{SD} \uparrow$ ) gradually in that the meaning in 2) is more condensed than 1) and 3) is more condensed than 2). Therefore, if the continuum of the three examples is combined with the figure mentioned above, it is reconfigured as the following (Figure 2): 


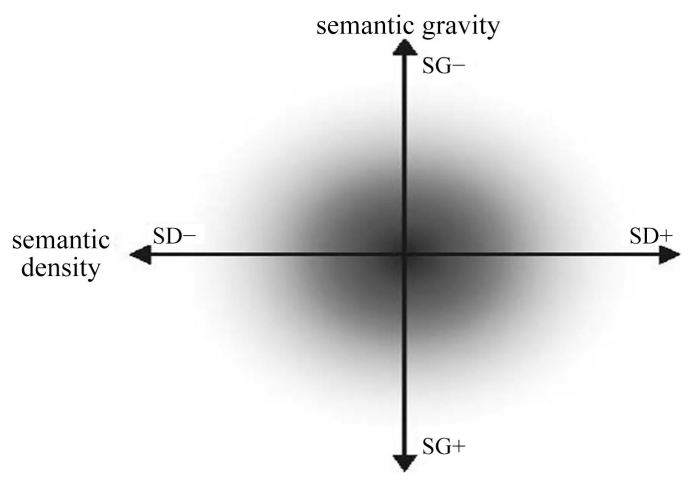

Figure 1. Semantic dimension of LCT (Maton, 2014: p. 196).

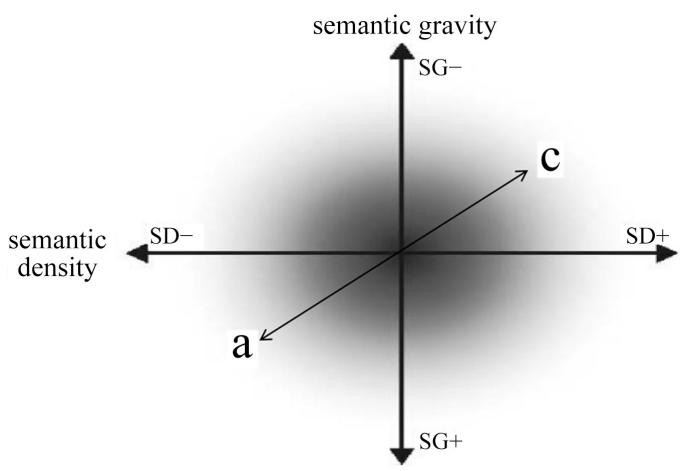

Figure 2. Revised semantic dimension of LCT.

The figure shows that the sequence through 1) to 3) is a dynamic process of moving from the most congruent 1 ) (SG+, SD-) to the most metaphorical 3) (SG-, SD+).

\section{Conclusion}

In summary, in supplementing Basil Bernstein's dichotomous viewpoint, Karl Maton puts forward the semantic dimension of LCT which regards meanings as a continuum. This continuum in terms of semantic density and semantic gravity is applicable to the explanation of grammatical metaphor in SFL, which sheds some light on the idea of SFL as appliable. This paper is another association of SFL theories with the constructs formulated by researchers in sociology, but a systematic delineation of relevant constructs with respect to the two fields needs to be further investigated in future researches.

\section{Conflicts of Interest}

The author declares no conflicts of interest regarding the publication of this paper.

\section{References}

Bernstein, B. (1970). A Socio-Linguistic Approach to Socialization: With Some Reference to Educability. In J. J. Gumperz, \& D. H. Hymes (Eds.), Directions in Sociolinguistics. New York: Holt, Rinehart and Winston. 
Bernstein, B. (1986). On Pedagogic Discourse. In J. G. Richardson (Ed.), Handbook of Theory and Research for the Sociology of Education. New York: Greenwood Press.

Bernstein, B. (1996). Pedagogy, Symbolic Control and Identity: Theory, Research, Critique. London: Taylor and Francis.

Bernstein, B. (2000). Pedagogy, Symbolic Control and Identity: Theory, Research, Critique (Revised Edition). Oxford: Rowman \& Littlefield.

Halliday, M. A. K. (1984). Language as Code and Language as Behaviour: A Systemic-Functional Interpretation of the Nature and Ontogenesis of Dialogue. In R. Fawcett, M. A. K. Halliday, S. M. Lamb, \& A. Makkai (Eds), The Semiotics of Culture and Language. London: Pinter.

Halliday, M. A. K. (1985). An Introduction to Functional Grammar. London: Edward Arnold.

Halliday, M. A. K. (1994). An Introduction to Functional Grammar (2nd ed.). London: Edward Arnold.

Halliday, M. A. K., \& Matthiessen, C. M. I. M. (2004). An Introduction to Functional Grammar (3rd ed.). London: Hodder Arnold.

Hu, A. Q. (2018). A Social Semiotic Study of Bernstein's Code Theory. Journal of Tianjin Foreign Studies University, 25, 84-94.

Martin, J. R. (2013). Embedded Literacy: Knowledge as Meaning. Linguistics and Education, 24, 23-37. https://doi.org/10.1016/j.linged.2012.11.006

Maton, K. (2013). Making Semantic Waves: A Key to Cumulative Knowledge-Building. Linguistics and Education, 24, 8-22. https://doi.org/10.1016/j.linged.2012.11.005

Maton, K. (2014). Knowledge and Knowers: Towards a Realist Sociology of Education. New York: Routledge. https://doi.org/10.4324/9780203885734

Wignell, P. (2007). Vertical and Horizontal Discourse and the Social Sciences. In F. Chirstie, \& J. R. Martin (Eds.), Language, Knowledge and Pedagogy: Functional Linguistic and Sociological Perspectives (pp. 184-204). London: Continuum.

Yang, B. (2019). Interpersonal Metaphor Revisited: Identification, Categorization, and Syndrome. Social Semiotics, 29, 186-203. https://doi.org/10.1080/10350330.2018.1425322

Zhu, Y. S. (2011). Influences of Bernstein's Theory of Pedagogic Sociology on Systemic Functional Linguistics. Foreign Language Education, 32, 6-12. 